\title{
Relative predation vulnerability of three juvenile (Age-0) North Pacific flatfish species: possible influence of nursery-specific predation pressures
}

\author{
Jena L. Lemke ${ }^{1,2,3, *}$, Clifford H. Ryer ${ }^{2}$ \\ ${ }^{1}$ Department of Fisheries and Wildlife, Oregon State University, Corvallis, Oregon 97331, USA \\ ${ }^{2}$ Fisheries Behavioral Ecology Program, Alaska Fisheries Science Center, National Marine Fisheries Service/National \\ Oceanic \& Atmospheric Association (NMFS/NOAA), Hatfield Marine Science Center, Newport, Oregon 97365, USA \\ ${ }^{3}$ Present address: ABR, Inc. PO Box 249, Forest Grove, Oregon 97116, USA
}

\begin{abstract}
Pleuronectid flatfish are generally thought to utilize stereotypical anti-predator behavior to reduce encounters with potential predators. In this study, we tested the relative vulnerability of 3 juvenile (Age-0) flatfish species to predation under controlled laboratory conditions. Predators consumed significantly more English sole Parophrys vetulus than either Pacific halibut Hippoglossus stenolepis or northern rock sole Lepidopsetta polyxystra in clear water (0 nephelometric turbidity units, NTU), suggesting differing anti-predator strategies and/or capabilities. In contrast to halibut and rock sole, which remained buried and inactive, English sole were often observed actively moving about. As a result, English sole were encountered more frequently by predators than the other 2 species, suggesting that they were more conspicuous to the predators. This was further evidenced by a higher frequency of stalk encounters for English sole, whereby the predators detected and approached them prior to prey flushing. However, as an estuarine-dependent species, English sole are generally exposed to lower densities of predators in an environment that tends to be highly turbid. When similar trials were conducted at higher turbidity (18 NTU), predation rates on English sole decreased to rates comparable to that for halibut and rock sole in clear water (0 NTU). Although English sole appeared more vulnerable to predation, their behavior may have evolved in response to, and be mitigated by, the turbid nature of the estuarine nursery environments to which they recruit, where predation pressure is significantly reduced in comparison to open coastal habitats.
\end{abstract}

KEY WORDS: Anti-predator behavior · Predator-prey interactions · Juvenile flatfish $\cdot$ Estuarine dependence $\cdot$ Turbidity

\section{INTRODUCTION}

Predation is the principal cause of mortality for young life stages of fishes (Houde 1987, 2002, Bailey \& Houde 1989) and thus a strong selective force for the development of anti-predator behaviors. Such behaviors mediate the probability of encounters with predators and, along with other post-encounter behavior, influence how vulnerable an individual is to predation. However, increased anti-predator behavior can be costly, resulting in lowered energy intake, as vigilant behavior and foraging are often mutually exclusive (Lima 1998). For juvenile fish with high metabolic demands, the cost of vigilance must be weighed against the benefits of being able to foraging efficiently. Anti-predator behaviors should therefore be adapted to reflect the level of predation risk as it varies over various temporal and spatial scales (Lima \& Dill 1990). In environments or conditions where a decreased probability of detection by predators exists, prey 
species may reduce or abandon anti-predator tactics (Magurran \& Seghers 1990).

Fish rely on a number of different types of cover as a refuge from predators; such structured habitats include aquatic macrophytes, seagrass beds, rocky reefs, sponges, and corals. Although not normally thought of with respect to this aspect, turbidity may function in an analogous manner. In turbid water for example, fish may increase foraging activity (Gregory \& Northcote 1993, Gregory 1994) and their use of high risk, open water habitats (Miner \& Stein 1996), and reduce the use of refuges i.e. structured habitats (Gradall \& Swenson 1982, Gregory 1993, Snickars et al. 2004). It is possible that fishes utilize 'turbidity as cover' to reduce the probability of detection by visual predators (Gregory 1993). In estuaries, sediments from upstream sources and run-off are transported and mixed during tidal changes, causing high turbidity. In such areas piscivory may be restricted, since turbidity impairs visibility over long distances.

Juvenile flatfish use a number of anti-predator tactics to reduce their probability of detection by invertebrate, vertebrate, and avian predators. Such anti-predator behaviors include cryptically matching substrates, burial, maintaining a low body profile against the substrate, and reducing activity in the presence of a predation threat. Juvenile flatfish in turbid environments, such as estuaries, might be expected to relax or abandon such anti-predator behaviors. English sole Parophrys vetulus, an 'estuarine-dependent' species that disproportionately recruits to estuaries in comparison to open coastal areas, may be an example of one such species (Olson \& Pratt 1973, Pearcy \& Myers 1974, Gunderson et al. 1990). In contrast, juvenile flatfish that recruit to less turbid, open coastal areas such as Pacific halibut Hippoglossus stenolepis and northern rock sole Lepidopsetta polyxystra, might be expected to have welldeveloped anti-predator strategies, as encounters with visual predators are more likely.

Differences in capabilities or the expression of antipredator behavior may directly influence the mortality of juvenile flatfish (Ryer et al. 2004). The goal of the present study was to determine if juvenile flatfish vulnerability to predation varies among the 3 species English sole, Pacific halibut, and northern rock sole. We hypothesized that English sole, an estuarinedependent species, may have relaxed anti-predator strategies in comparison to halibut and rock sole. As a result, we expected that English sole would be encountered more frequently than both halibut and rock sole, resulting in higher predation rates. Further, we hypothesized that in turbid water trials, predation rates on English sole would be similar to those on halibut and rock sole, since encounters with predators would be less.

\section{MATERIALS AND METHODS}

Fish collection and maintenance. Age-0 halibut (<60 mm total length, TL) and rock sole (<60 mm TL) were collected in Chiniak Bay, Kodiak Island, Alaska $\left(57^{\circ} 40^{\prime} \mathrm{N}, 152^{\circ} 30^{\prime} \mathrm{W}\right)$ using a small beam trawl $(2 \mathrm{~m}$ wide beam, $3 \mathrm{~mm}$ mesh) in July and August 2004. Age2 halibut $(<305 \mathrm{~mm}$ TL) were collected as Age-0 juveniles in the same location in 2002 and were raised in the laboratory. These fish were maintained at the Kodiak Fisheries Research Center for 2 to $3 \mathrm{~d}$ before being transported by air in insulated containers to the Fisheries Behavioral Ecology Program's laboratory at the Hatfield Marine Science Center (HMSC) in Newport, Oregon. Age-0 English sole (<80 mm TL) were collected in Yaquina Bay, Oregon, using a small otter trawl (4 m long, $3 \mathrm{~mm}$ mesh) in May and June 2004. All Age0 flatfish were maintained at the NMFS laboratory at the HMSC in $2.3 \mathrm{~m}$ diameter tanks with a thin layer of light colored sand at $9^{\circ} \mathrm{C}\left( \pm 1^{\circ} \mathrm{C}\right)$ in flow-through seawater. As these fish may be accustomed to dark sand in their respective nursery areas, they were acclimated to light sand for a period of at least 1 mo before being used in predation trials. Age-0 flatfish were fed to satiation thrice weekly with commercially available fish food pellets (Bio-Diet, $2 \mathrm{~mm}$ ) supplemented with krill. Age-2 halibut predators were maintained in large $(4.4 \mathrm{~m})$ pools at $9^{\circ} \mathrm{C}\left( \pm 1^{\circ} \mathrm{C}\right)$ in flow-through seawater. Age- 2 halibut were fed a diet of gel food and squid Loligo spp. To reacquaint them with live prey, Age-2 halibut diets were converted to live Age-0 English sole $3 \mathrm{wk}$ prior to initiation of the predation trials. We assumed that training our predators with Age-0 English sole did not predispose them to display increased foraging efficiency on English sole in comparison to halibut and rock sole in our experiments. In a previous study, regardless of the prey species, halibut predators displayed similar search behavior with slow, short movements along the bottom interspersed with short pauses even though they were only trained with 1 prey species (Ryer et al. 2004). All fishes were adapted to a diurnal cycle of $12 \mathrm{~h}$ of light (07:00 to 19:00 h) and $12 \mathrm{~h}$ darkness (19:00 to 07:00 h).

Predation trials. Predation trials were conducted in $2.9 \mathrm{~m}$ diameter circular arenas with filtered, flowthrough, $9^{\circ} \mathrm{C}\left( \pm 1^{\circ} \mathrm{C}\right)$ seawater at a depth of $30 \mathrm{~cm}$. The entire bottom of each arena was covered with a 2:1 mixture of coarse $(1.0 \mathrm{~mm})$ and medium $(0.5 \mathrm{~mm})$, light-colored sand to a depth of $3 \mathrm{~cm}$ to allow juvenile flatfish to bury normally. The sand was siphoned clean and raked smooth $24 \mathrm{~h}$ prior to the start of the trials. For the duration of the trials for each species, 2 Age-2 halibut predators were maintained in each of the experimental arenas. It had been determined in a previous study that predators were more reliable, exhibit- 
ing more consistent foraging behavior, when used in pairs (Ryer et al. 2004). TL of halibut predators ranged from 360 to $380 \mathrm{~mm}(\bar{x}=370, \mathrm{SE}=2.6)$. Prior to commencement of the trials, 30 prey were measured (TL) and deprived of food for $48 \mathrm{~h}$. Prey were released into the experimental arena in complete darkness and allowed a $15 \mathrm{~min}$ acclimation period. At this point, the lights were turned on and the trial began. All trials were videotaped from overhead for the duration of the 30 min trial. Afterwards, the remaining prey fish were recovered by methodically raking the arena 3 times, each time by a different person (to ensure complete recovery) and removing them by dip-nets as they were encountered. They were then re-measured and returned to separate holding tanks to ensure that they were not re-used in subsequent trials.

We conducted 6 replicate trials for each of the 3 prey species, English sole, Pacific halibut, and northern rock sole. Total fish lengths ranged from 50 to $80 \mathrm{~mm}(\bar{x}=69$, $\mathrm{SE}=0.49)$ for Age-0 English sole, from 50 to $80 \mathrm{~mm}(\bar{x}=$ $66, \mathrm{SE}=0.46$ ) for Age-0 halibut, and from 50 to $80 \mathrm{~mm}$ $(\bar{X}=66, \mathrm{SE}=0.10)$ for Age-0 rock sole. Total fish lengths differed between the 3 species $\left(F_{[2,15]}=19.73, \mathrm{p}<\right.$ 0.001), with English sole significantly larger than the other 2 species (Tukey multiple comparisons, $\mathrm{p}<0.05$ ). This effect was not meaningful, as no evidence of size selection was observed in the experiments. No significant difference was detected between the mean size of the prey before and after the predation trials.

Predator activity was quantified to adjust the number of prey consumed per unit effort as the total time the 2 predators spent foraging over the duration of the trial. Activity was scored as the time spent exhibiting 1 of the following behaviors: buried or inactive (scored as 0 ), non-foraging swimming (scored as 1), and foraging (scored as 2). Halibut predators exhibit distinctive foraging behavior, with slow, short movements along the bottom interspersed with short pauses (Ryer et al. 2004). Pauses of less than $30 \mathrm{~s}$ were not uncommon when predators were foraging; therefore, predators were scored as being inactive only if a pause was $30 \mathrm{~s}$ or longer in duration. If a predator buried, however, it was scored as being inactive regardless of the duration of such burial. The first 15 encounters by the 2 predators collectively were enumerated to determine the amount of time taken to encounter half the prey. These encounters were also scored depending on whether (1) a stationary prey flushed when approached by a predator ('flush'), (2) a predator detected and stalked a stationary prey ('stalk'), (3) a predator ambushed an actively moving prey ('ambush'), or (4) another predator joined in the pursuit of a prey engaged by the other predator ('facilitation'). For flush encounters, the distance between the predator and prey at the initiation of the flush was measured. Further, the distance the prey traveled after it flushed was measured from the point at which the prey initiated a flush to the first point of contact with the sediment. This measure was used because the species exhibited different escape behavior. English sole tended to make several short 'hops' along the bottom before stopping; rock sole tended to make 1 short flight, before stopping and burying, while halibut often made a small 'hop', followed by a short flight before stopping and burying. We also recorded whether or not the predator initiated pursuit, as well as the outcome (i.e. escape or capture). Data were analyzed using standard analysis of variance (ANOVA; Ramsey \& Schafer 2002). Effects were considered significant at the $\mathrm{p}=0.05$ level and, when observed, were analyzed using Tukey's HSD test for multiple comparisons.

Turbid trials on English sole. To determine if turbid water would decrease predation rates on English sole, we conducted 2 series of predation trials in which turbidity was manipulated. The first series of trials was conducted concurrently with the above described predation trials, augmenting the clear water (0 NTU) English sole trials with the addition of 2 turbid treatments (4 and 8 NTU). The total length of the halibut predators was the same as in the previous trials while the total length of English sole prey ranged from 50 to $80 \mathrm{~mm}$ $(\bar{x}=68, \mathrm{SE}=0.31)$. Based on the results of these trials, a second series of trials was conducted at a higher turbidity level. These were conducted in a similar manner, but were scaled down to smaller (2.3 m diameter) circular experimental arenas, and conducted for $1 \mathrm{~h}$. In these trials, there were 2 treatments, 0 and 18 NTU. The total length for halibut predators ranged from 260 to $305 \mathrm{~mm}(\bar{x}=294 \mathrm{~mm}, \mathrm{SE}=5.9)$, while the total length for English sole prey ranged from 40 to $60 \mathrm{~mm}(\bar{X}=$ $50 \mathrm{~mm}, \mathrm{SE}=0.79$ ), maintaining the approximately $6: 1$ predator:prey total length ratio of the prior predation trials. For all turbid trials, a kaolin clay solution (120 l) was mixed, and the supernatant was siphoned into the experimental arenas, creating the desired turbidity. Water flow was diverted, creating static conditions within the experimental arenas and ensuring a constant turbidity throughout the duration of the trial. In clear-water trials, filtered seawater (120 l) was siphoned into the experimental arenas as a control. We conducted 6 replicate trials of each treatment for the first experiment, and 4 replicate trials of each treatment for the second experiment.

\section{RESULTS}

During the 30 min predation experiment, there was a significant effect of species on the number of prey consumed $\left(F_{[2,17]}=41.3, p<0.0001\right)$. More juvenile 
English sole were consumed than either juvenile halibut or rock sole. On average, $52 \%$ (SE $=5.4$ ) of the English sole were consumed in comparison to $16 \%$ of the rock sole $(\mathrm{SE}=1.8)$ and $8 \%$ of the halibut $(\mathrm{SE}=$ 2.7). Predators spent more time foraging for English sole $(\bar{x}=43 \mathrm{~min}, \mathrm{SE}=93.7)$ than for either halibut $(\bar{x}=$ $18 \mathrm{~min}, \mathrm{SE}=104.1)$ or rock sole $(\bar{x}=27 \mathrm{~min}, \mathrm{SE}=$ $\left.114.4 ; F_{[2,17]}=9.52, \mathrm{p}=0.0021\right)$. When adjusted for predator effort, significantly more English sole were consumed $\mathrm{min}^{-1}$ foraging by the predators than either halibut or rock sole $\left(F_{[2,17]}=6.49, p=0.0093\right.$; Fig. 1). Significantly more English sole were encountered $\mathrm{min}^{-1}$ foraging by the predators than rock sole, while encounters of halibut did not differ significantly from those of the other 2 species $\left(F_{[2,17]}=3.80, \mathrm{p}=0.0456\right.$; Tukey multiple comparisons $\mathrm{p}<0.05$; Fig. 2). However, the distributions of different encounter types (flush, stalk, ambush, facilitation) differed significantly between the 3 species $\left(\chi^{2}=21.59, p=0.0014\right)$. The majority of these encounters were flush encounters for each of the species (average of $57 \%$ of the encounters for English sole and 78 and $77 \%$ for halibut and rock sole, respectively: Fig. 3). Most of the difference in encounter types between English sole and both halibut and rock sole was in the number of stalk encounters $(29 \%$ of the total encounters of English sole in comparison to 8 and $17 \%$ of the encounters with halibut and rock sole, respectively), suggesting that English sole were more conspicuous to the predators.

For flush encounters, the distance from the predator when the prey initiated its flight did not differ significantly among the 3 prey species $\left(F_{[2,17]}=2.64, \mathrm{p}=\right.$ 0.1039 ). On average, this distance was $18 \mathrm{~cm}$ for rock sole, $19 \mathrm{~cm}$ for English sole and $23 \mathrm{~cm}$ for halibut. However, once a flush was initiated, halibut $(\bar{X}=23.8 \mathrm{~cm}$, $\mathrm{SE}=1.5)$ fled significantly further than both English sole $(\bar{x}=18.6 \mathrm{~cm}, \mathrm{SE}=0.8)$ and rock sole $(\bar{x}=15.3 \mathrm{~cm}$, $\left.\mathrm{SE}=1.4 ; F_{[2,17]}=11.86, \mathrm{p}=0.0008\right)$. This distance was measured $(\mathrm{cm})$ from the point at which the prey initiated a flush to its first point of contact with the sediment. Once flushed, rock sole were most likely to be pursued by the predators while halibut were least likely to be pursued. Pursuit of English sole did not significantly differ from that of the other 2 species $\left(F_{[2,17]}=\right.$ $3.68, \mathrm{p}=0.0501)$. Predators struck at English sole $(\bar{x}=$ 29.5 strikes, $\mathrm{SE}=6.52 .7$ ) significantly more times during the trial than at either halibut $(\bar{x}=14.5$ strikes, $\mathrm{SE}=$ 5.71.6) or rock sole $\left(\bar{x}=9.3\right.$ strikes, $\mathrm{SE}=4.02 .3 ; F_{[2,17]}=$ $21.7, \mathrm{p}<0.0001)$.

Contrary to expectations, in trials with low turbidity (4 NTU), a slight but non-significant increase in the number of prey consumed was observed in comparison to trials with no turbidity (0 NTU; Fig. 4). This was most probably due to increased predator effort, quan-

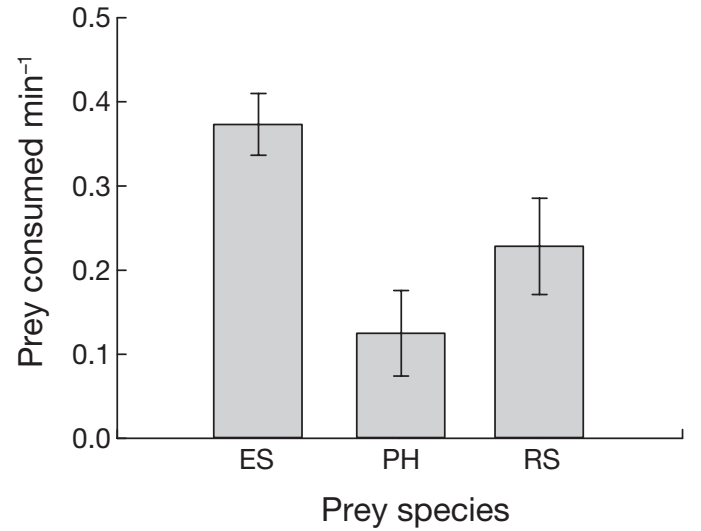

Fig. 1. Hippoglossus stenolepis foraging for Parophrys vetulus, H. stenolepis, and Lepidopsetta polyxystra. Mean $( \pm \mathrm{SE})$ number of Age-0 English sole (ES), Pacific halibut (PH) or rock sole (RS) consumed per unit effort by Age-2 halibut predators during a $30 \mathrm{~min}$ trial in $2.9 \mathrm{~m}$ arenas in clear water (0 nephelometric turbidity units, NTU)

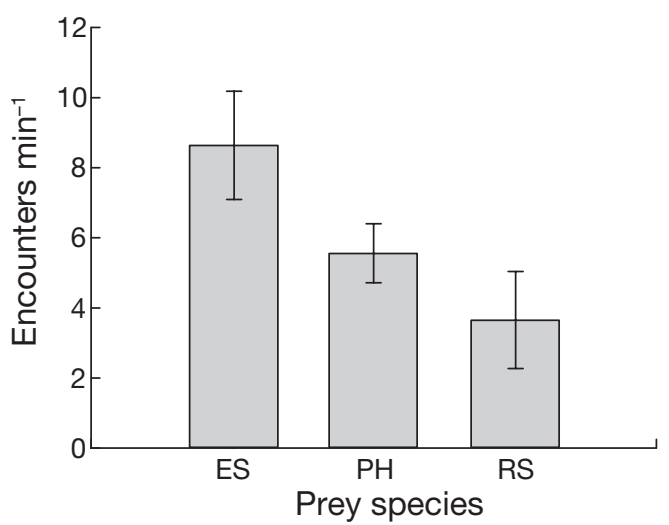

Fig. 2. Hippoglossus stenolepis foraging for Parophrys vetulus, H. stenolepis, and Lepidopsetta polyxystra. Mean $( \pm \mathrm{SE})$ number of prey encounters min $^{-1}$ that Age-2 halibut predators spent foraging for Age-0 English sole (ES), Pacific halibut $(\mathrm{PH})$, or rock sole (RS) prey during a $30 \mathrm{~min}$ trial in $2.9 \mathrm{~m}$ arenas in clear water (0 NTU)

tified by number of minutes spent foraging. On average, predators spent significantly less time foraging in clear water $(\bar{X}=43 \mathrm{~min}, \mathrm{SE}=93.7)$ than in turbid water $\left(\bar{x}=52 \mathrm{~min}, \mathrm{SE}=31.0 ; 1\right.$-way ANOVA on ranks: $F_{[1,11]}$ $=5.05, p=0.0484)$. At higher turbidity (8 NTU), there was suggestive evidence of a negative turbidity effect on the number of English sole consumed across the 3 turbidity levels $\left(F_{[2,17]}=3.34, \mathrm{p}=0.0632\right)$. In our second set of trials with 0 and 18 NTU treatments, we observed a significant decrease in the number of prey consumed with increased turbidity $\left(t_{6}=5.38, \mathrm{p}=\right.$ 0.0017). At the highest turbidity (18 NTU), predation on English sole was not significantly different than predation on either halibut or rock sole in clear water $\left(0 \mathrm{NTU} ; F_{[2,15]}=3.29, \mathrm{p}=0.0699 ;\right.$ Fig. 4$)$. 


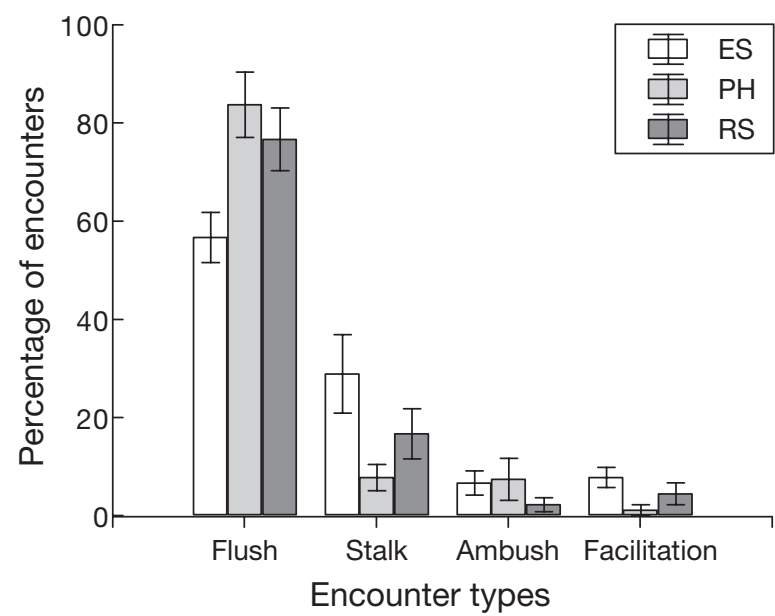

Fig. 3. Hippoglossus stenolepis foraging for Parophrys vetulus, H. stenolepis, and Lepidopsetta polyxystra. Mean $( \pm \mathrm{SE})$ percentage encounters with Age-0 English sole (ES), Pacific halibut (PH), or rock sole (RS) by Age-2 halibut predator during a $30 \mathrm{~min}$ trial in $2.9 \mathrm{~m}$ arenas. (For description of encounter types see 'Materials and methods - Predation trials')

\section{DISCUSSION}

The 3 species of juvenile flatfish studied, clearly have different vulnerabilities to predation that reflect species-level variation in anti-predator strategies and/or capabilities. English sole were more vulnerable to predation than halibut and rock sole, whether quantified as the number of prey consumed or consumption per unit effort. The predators remained engaged by the English sole throughout the trials, as they were almost constantly encountering this prey. In halibut

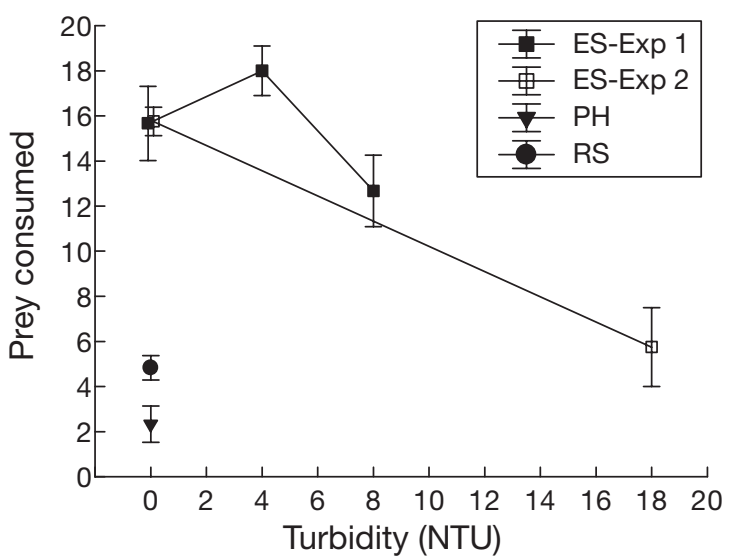

Fig. 4. Pacific halibut Hippoglossus stenolepis foraging for English sole Parophrys vetulus (ES). Mean $( \pm$ SE) number of Age-0 English sole consumed by Age-2 halibut predators during a $30 \mathrm{~min}$ trial in $2.9 \mathrm{~m}$ arenas (Expt 1), and during a $30 \mathrm{~min}$ trial in $2.3 \mathrm{~m}$ arenas (Expt 2). Data from trials conducted with Age-0 Pacific halibut (PH) and rock sole Lepid opsetta polyxystra (RS) are included for comparison and rock sole trials, longer periods of time passed between encounters, and predators often stopped foraging before the end of the trial, either burying or engaging in non-foraging swimming behavior around the tank.

The elevated vulnerability of English sole to predation results from significantly more encounters in comparison to the other 2 prey species. In clear water, where we could quantify encounters between predators and prey, juvenile English sole were encountered significantly more than the other 2 species, with a higher percentage of these encounters occurring as 'stalks', i.e. a stationary prey visible on the surface being detected and pursued by a predator. The higher percentage of such encounters indicates that English sole are more conspicuous to the predators than the other 2 prey species. English sole seem less likely to employ stereotypical flatfish anti-predator behaviors, or they may have a reduced ability to display such behaviors. Recent laboratory experiments with these 3 species demonstrated that English sole are indeed less likely to be buried: they adopt a raised body posture, with head elevated off the bottom, and are more active in the presence of a predator than the other 2 prey species (Lemke \& Ryer 2006). To a human observer, English sole were clearly visible lying motionless on the substrate as well as actively moving around the tank during the course of the trials. This type of behavior was rarely observed in trials with halibut and rock sole, as these prey were generally only visible when flushed by the predators. The more conspicuous English sole were also more likely to be attacked by the predators, as reflected by the number of strikes made on them. These results are similar to those of another study in which an average of $79 \%$ of attacks on juvenile winter flounder by Age-1 (271-345 mm TL) summer flounder occurred when the prey were visible on the surface, while an average of $33 \%$ occurred after the prey had been actively moving along the bottom (Manderson et al. 2000).

The distances between predator and prey when the prey decided to flee, known as flight initiation distance, did not differ significantly between the 3 prey species. It may be more beneficial for juvenile flatfish to rely on burial and crypsis rather than flushing immediately that the predator is detected. The latter behavior would be likely to alert the predator to the presence of the prey. Based on an economic model, flight initiation distance should increase with increased risk of predation and decrease with increased cost of flight (Ydenberg \& Dill 1986). Another recent model, which predicts optimal strategies for cryptic prey against pursuit predators, predicts that prey should either flee immediately upon seeing the predator, or wait to flush until the predator has initiated an 
attack (Broom \& Ruxton 2005). In addition, this decision may also be based on the prey's relative likelihood of escape. In our study it was difficult to determine when the prey first became aware of the predator, thus making it difficult to determine if the prey were fleeing immediately or waiting until an attack was made. Once flushed, however, halibut, which tend to rely on flight to escape predators, moved significantly further away from the predator than either English sole or rock sole. Both, halibut and rock sole initiated flight, settled, and tended to bury immediately once flushed by the predators. Both species had to be physically extracted (i.e. raked) from the sand at the termination of the trials.

Juvenile English sole may have relaxed antipredator behavior due to the turbid nature of the estuarine nursery areas to which they preferentially recruit. Such areas offer reduced risk of predation by visual predators, since foraging efficiency is decreased; they also offer accelerated growth as a result of warmer temperatures and increased food resources. Field studies have demonstrated that juvenile stages of fish profit from reduced risk to piscivores (Ritchie 1972, Blaber \& Blaber 1980, Gradall \& Swenson 1982, Guthrie 1986). For example, Walsh et al. (1999) found that, regardless of season, the highest densities of small flatfish were found in the upper estuarine areas of the Newport River and Back Sound (North Carolina) associated with the highest turbidities. Similarly, Power et al. (2000) found a positive relationship between suspended solid concentrations and species abundances for juvenile flounder and dab in the Thames River estuary. The range of turbidities in which our experiments were conducted was similar to that observed near our juvenile flatfish collection sites. In Yaquina Bay where English sole were collected, turbidity ranged from 0.4 to $19.5 \mathrm{NTU}(\bar{x}=8.4, \mathrm{SE}=1.7$; J.L.L. unpubl. data). Similar average turbidity ranges were observed in 2 studies that related juvenile fish distribution to estuarine habitat characteristics such as turbidity (1 to $15 \mathrm{NTU}$, Blaber \& Blaber 1980; 4.9 to 19 NTU, Walsh et al. 1999). While no turbidity data (in NTUs) is available for the Kodiak Island halibut and rock sole collection sites, we observed 30 to $40 \mathrm{ft}$ ( $\sim 9$ to $12 \mathrm{~m}$ ) underwater visibility at the time of the collections, indicating very low turbidity in these areas.

Our trials in clear, non-turbid water may have therefore differentially effected English sole and increased their mortality, since this species has adapted its antipredator behavior to reflect the reduced risk of predation offered by turbidity in its natural environment. Although mortality increased slightly at very low turbidity levels (4 NTU), at a more elevated level of turbidity (18 NTU) English sole underwent a reduction in mortality, with rates similar to those experienced by halibut and rock sole in clear water (0 NTU). The significant decrease in predation on English sole at high turbidities may also be attributable to a reduction in the foraging efficiency of the predators. In fact, a number of studies have demonstrated that increased turbidity decreases the foraging efficiency of piscivores (Johnson \& Hines 1999, Reid et al. 1999, Vogel \& Beauchamp 1999, De Robertis et al. 2003). Although we do not know the extent to which predator foraging efficiency was affected by turbidity, it is likely that any visually foraging piscivore would be affected in a similar manner. At the higher turbidity levels, we were limited in our ability to observe the behavior of both the predators and the juvenile English sole. Thus, we were unable to determine which behavioral mechanisms render English sole less vulnerable to predation as turbidity increases. While these experiments were not conducted with halibut and rock sole due to a lack of sufficient fish, we suspect that these 2 species would similarly have decreased mortality in elevated turbidity levels, although such conditions are less frequently encountered by these species.

The turbid nature of estuaries clearly affects the mechanisms of predator-prey interactions, and can have an effect on both the pre-encounter and postencounter processes. Aspects of prey encounters with visual predators include visual range of the predator, visual field angle, speed at which the predator is traveling, and density of the prey. Water clarity, the size and apparent contrast of the prey, and surface light all affect the visual range of the predator (Aksnes \& Giske 1993). Suspended particles in the water column (i.e. turbidity) decrease light intensity and light scattering, reducing contrast and the clarity of the prey image (Hinshaw 1985, Giske et al. 1994). The visual range of the predator, therefore, decreases with increasing turbidity, thus decreasing the encounter rate with prey. Further, when prey are encountered, they have to travel a shorter distance to move out of the visual range of the predator in comparison to clear water, and thus post-encounter processes such as flight are affected.

In conclusion, we have demonstrated that Age-0 English sole have an increased vulnerability to predation by halibut predators compared to Age-0 halibut and rock sole, due to an increased likelihood that they will be encountered by predators. In addition, English sole were stalked more frequently by the predators than were either halibut or rock sole, indicating that they are more conspicuous to the predators. Relaxed anti-predator behavior may have been learned, developed, or evolved through the dependence of English sole on estuaries, where they rely upon turbidity as cover from predators. The turbidity in such areas probably provides cover from piscivorous predators, allowing English sole to relax such behaviors. In order to 
validate this hypothesis, the anti-predator behavior of a number species inhabiting estuarine areas should be compared to that of species inhabiting coastal, marine habitats, where turbidity is less common.

Acknowledgements. We thank E. Munk, A. Abookire and T. Tripp for their assistance in collecting juvenile flatfishes in Kodiak, Alaska. We thank M. Petrie, M. Spencer, M. Ottmar, P. Iseri, S. Haines, T. Hurst and K. Boersma for their assistance with laboratory experimentation, collection of juvenile flatfishes, and logistical support. G. Boehlert, A. Stoner and I. Fleming provided comments on early drafts of this manuscript, and supported the MS research of J.L.L. at Oregon State University. This work was funded in part by a grant from the North Pacific Research Board, grant \#R0301. J.L.L. was supported by this grant as well as by the Coastal Oregon Marine Experimental Station of OSU.

\section{LITERATURE CITED}

Aksnes DL, Giske J (1993) A theoretical model of aquatic visual feeding. Ecol Model 67:233-250

Bailey KM, Houde ED (1989) Predation on eggs and larvae of marine fishes and the recruitment problem. Adv Mar Biol 25:1-83

Blaber SJM, Blaber TG (1980) Factors affecting the distribution of juvenile estuarine and inshore fishes. J Fish Biol 17: 143-162

Broom M, Ruxton G (2005) You can run - or you can hide: optimal strategies for cryptic prey against pursuit predators. Behav Ecol 16:534-540

De Robertis A, Ryer CH, Veloza A, Brodeur RD (2003) Differential effects of turbidity on prey consumption of piscivorous and planktivorous fish. Can J Fish Aquat Sci 60:1517-1526

Gibson RN, Robb L, Wennhage H, Burrows MT (2002) Ontogenetic changes in depth distribution of juvenile flatfishes in relation to predation risk and temperature on a shallowwater nursery ground. Mar Ecol Prog Ser 229:223-244

Giske J, Aksnes DL, Fiksen O (1994) Visual predators, environmental variables, and zooplankton mortality risk. Vie Milieu 44:1-9

Gradall KS, Swenson WA (1982) Responses of brook trout and creek chubs to turbidity. Trans Am Fish Soc 111:392-395

Gregory RS (1993) Effect of turbidity on the predator avoidance behavior of juvenile chinook salmon (Oncorhynchus tshawytscha). Can J Fish Aquat Sci 50:241-246

Gregory RS (1994) The influence of ontogeny, perceived risk of predation and visual ability on the foraging behavior of juvenile chinook salmon. Belle W Baruch Libr Mar Sci 18:271-284

Gregory RS, Northcote TG (1993) Surface, planktonic, and benthic foraging by juvenile chinook salmon (Oncorhynchus tshawytscha) in turbid laboratory conditions. Can J Fish Aquat Sci 50:233-240

Gunderson DR, Armstrong DA, Shi Y, McConnaughey RA (1990) Patterns of estuarine use by juvenile English sole (Parophrys vetulus) and Dungeness crab (Cancer magister). Estuaries 13:59-71

Guthrie DM (1986) Role of vision in fish behavior. In: Fisher TJ (ed) The behavior of teleost fishes. Groom Helm, London, p 75-113

Hinshaw, JM (1985) Effects of illumination and prey contrast on survival and growth of larval yellow perch Perca flavescens. Trans Am Fish Soc 114:540-545

Editorial responsibility: Kenneth Heck (Contributing Editor), Dauphin Island, Alabama, USA
Houde ED (1987) Fish early life dynamics and recruitment variability. Am Fish Soc Symp 2:17-29

Houde ED (2002) Mortality. In: Fuiman LA, Werner RG (eds) Fishery science: the unique contributions of early life stages. Blackwell Publishing, Oxford, p 64-87

Johnson JE, Hines RT (1999) Effect of suspended sediment on vulnerability of young razorback suckers to predations. Trans Am Fish Soc 128:648-655

Lemke JL, Ryer CH (2006) Risk sensitivity in three juvenile (Age-0) flatfish species: Does estuarine dependence promote risk-prone behavior? J Exp Mar Biol Ecol 333:172-180

Lima SL (1998) Nonlethal effects in the ecology of predatorprey interactions. BioScience 48:25-34

Lima SL, Dill LM (1990) Behavioral decisions made under the risk of predation: a review and prospectus. Can J Zool 68: $619-640$

Magurran AE, Seghers B (1990) Population differences in predator recognition and attack cone avoidance in the guppy (Poecilia reticulata). Anim Behav 40:443-452

Manderson JP, Phelan BA, Stoner AW, Hilbert J (2000) Predator-prey relations between age-1+ summer flounder (Paralichthys dentatus, Linnaeus) and age-0 winter flounder (Pseudopleuronectes americanus, Walbaum): predator diets, prey selection, and effects of sediments and macrophytes. J Exp Mar Biol Ecol 251:17-39

Miner JG, Stein RA (1996) Detection of predators and habitat choice by small bluegills: effects of turbidity and alternative prey. Trans Am Fish Soc 125:97-103

Olson RE, Pratt I (1973) Parasites as indicators of English sole (Parophrys vetulus) nursery grounds. Trans Am Fish Soc 102:405-411

Pearcy WG, Myers SS (1974) Larval fishes of Yaquina Bay, Oregon: a nursery ground for marine fish? Fish Bull US 72: 201-213

Power M, Attrill MJ, Thomas, RM (2000) Environmental factors and interactions affecting the temporal abundance of juvenile flatfish in the Thames Estuary. J Sea Res 43:135-149

Ramsey FL, Schafer DW (2002) The statistical sleuth: a course in the methods of data analysis. Duxbury Press, New York

Reid SM, Fox MG, Whillans TH (1999) Influence of turbidity of piscivory in largemouth bass (Micropterus salmoides). Can J Fish Aquat Sci 56:1362-1369

Ritchie JC (1972) Sediment, fish, and fish habitat. J Soil Water Conserv 27:124-125

Rooper CN, Gunderson DR, Armstrong DA (2003) Patterns in the use of estuarine habitat by juvenile English sole (Pleuronectes vetulus) in four eastern North Pacific estuaries. Estuaries 26:1142-1154

Ryer CH, Stoner AW, Titgen RG (2004) Behavioral mechanisms underlying the refuge value of benthic habitat structure for two flatfishes with differing anti-predator strategies. Mar Ecol Prog Ser 268:231-243

Snickars M, Sandström A, Mattila J (2004) Antipredator behaviour of 0+ year Perca fluviatilis: effect of vegetation density and turbidity. J Fish Biol 65:1604-1613

Vogel JL, Beauchamp DA (1999) Effects of light, prey size, and turbidity on reaction distances of lake trout (Salvelinus namaycush) to salmonid prey. Can J Fish Aquat Sci 56:1293-1297

Walsh HJ, Peters DS, Cyrus DP (1999) Habitat utilization by small flatfishes in a North Carolina estuary. Estuaries 22(3B):803-813

Ydenberg RC, Dill LM (1986) The economics of fleeing from predators. In: Rosenblatt JS, Beer C, Busnel MC, Slater PJB (eds) Advances in the study of animal behaviour, Vol 16. Academic Press, Orlando, p 229-249 